\title{
Interview with Prof. Akira Matsumura: the accelerator-based clinical trial of BNCT for melanoma will be started in 2019
}

Received: 15 November 2018; Accepted: 25 November 2018; Published: 04 December 2018.

doi: $10.21037 /$ tro.2018.11.04

View this article at: http://dx.doi.org/10.21037/tro.2018.11.04

\section{Editor's note}

The 18th International Congress on Neutron Capture Therapy (ICNCT) was successfully held in Taipei, Taiwan from October 28 to November 2. Researchers came from different countries, such as Japan, USA, Italy, Argentina, Germany, Finland, etc. to attend this grand meeting. The gathering of researchers in the fields of radiology, chemistry, physics, nuclear medicine and pathology has enriched and stimulated discussion during the meeting. AME editorial team had the honor to interview Prof. Akira Matsumura from the University of Tsukuba. Prof. Matsumura gave a speech on "Current status of i-BNCT project at Tsukuba \& Tokai”. Through his speech, we learned that his team is already performing preclinical trail for malignant melanoma and will conduct phase I clinical trial in the coming year.

\section{Expert introduction}

Prof. Akira Matsumura (Figure 1) is a Clinical Professor and Chairman of the Department of Neurosurgery at the University of Tsukuba and the Director of the University of Tsukuba Hospital. He is also the Division Chairman of BNCT in the Proton Medical Research Center at the University of Tsukuba Hospital and the Project Leader of i-BNCT project, which is supported by International Strategic Zone, METI \& Cabinet office of Japan.

In 1984-1986, he worked as an Assistant Doctor of Neurosurgery at the Universität Göttingen, Germany and obtained "Doktor der Medizin". In 1995, he worked in Max-Planck Institut für biophysikalische ChemieBiomedizinische NMR (BiomedNMR) in Göttingen, Germany. He was the President of International Society for Neutron Capture Therapy (ISNCT) from 2012 to 2014. $\mathrm{He}$ is also a member of ISNCT and Japanese Society for Neutron Capture Therapy (JSNCT).

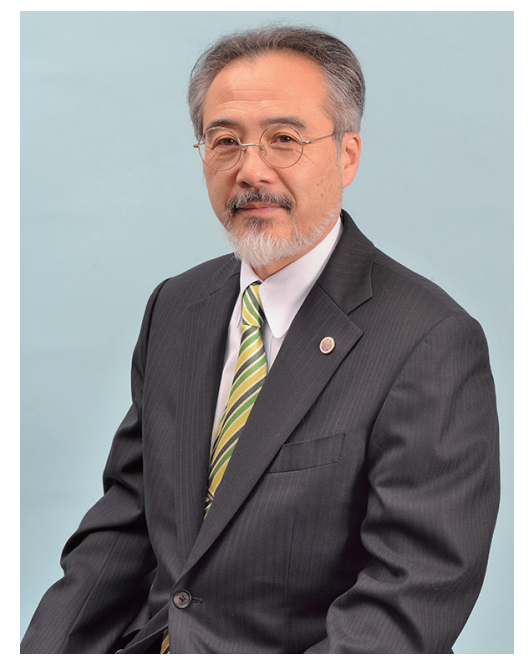

Figure 1 Prof. Akira Matsumura.

\section{Interview (Figure 2)}

TRO: Could you briefly share with us your speech on "Current status of i-BNCT project at Tsukuba \& Tokai"?

Prof. Matsumura: I was involved in BNCT since 1992. At that time, I was an Assistant Professor at the University of Tsukuba and I joined BNCT research team of late Prof. Hatakana who was the pioneer of BNCT since 1970's in Japan. We used research reactor JRR-2 at Tokai JAERI and after it was shut down, we used JRR-4 alternatively. We have done both basic and clinical research on BNCT, using research reactor for about 20 years. However, BNCT at the nuclear reactor took huge time and effort to perform the treatment because the reactor was not near hospital and not for clinical use. That is why we wanted to have acceleratorbased BNCT facilities, which can be used in the hospitals. Then the application of BNCT will grow. This is what we have planned at that time. 


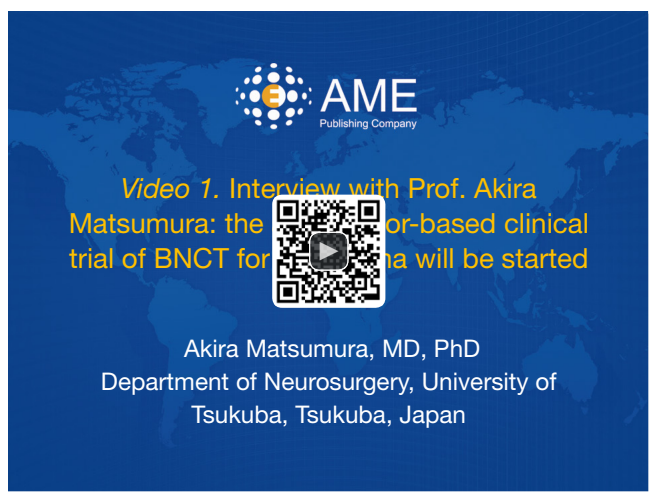

Figure 2 Interview with Prof. Akira Matsumura: the acceleratorbased clinical trial of BNCT for melanoma will be started in 2019 (1). Available online: http://www.asvide.com/article/view/28680

In 2005-2007, I got a big research grant to build up an accelerator for BNCT, collaborating with an accelerator physicist. Unfortunately, this machine could not be realized. From 2013 till now, we are conducting a new project, collaborating with the researchers from High Energy Accelerator Research Organization known as KEK and Japan Atomic Energy Agency (JAEA) to build up an accelerator for BNCT, which is safe in terms of radiation contamination of the machine and treatment room. The expert of KEK recommended the use of $8 \mathrm{MeV}$ for the accelerator because it was below the threshold of the radioactivation of the metal used. This was one of the big hurdle for us to overcome the high current enough for the treatment of the BNCT. Finally, we have reached enough current for clinical use this year and we are preparing to start the clinical trial next year.

\section{TRO: As we know you are the project leader, what is the motivation for you and your colleagues to start $i-B N C T$ project back in 2013?}

Prof. Matsumura: As we had very promising clinical results with aggressive brain tumor called Glioblastoma, namely at the time with the standard therapy, the patients had overall median survival of less than 12 months. In contrast, the patients who have received BNCT, the overall median survival was 25 months. It is double time longer than the standard therapy. I was very confident about that clinical result. We have never seen such an effective treatment for Glioblastoma, so that the urgent need for accelerator was evident.
We live in Tsukuba Science City where we have High Energy Accelerator Research Organization and could easily get a very powerful accelerator team from KEK and experts for neutron beam from JAEA. A powerful research project team was then established about 6 years ago. We created a small group with medical physicians and physicists. We planned to create a very compact and safe accelerator for clinical use. But it took time to complete the accelerator. Now we finished the accelerator itself. We started the preclinical trail this year. Next year, we will start the clinical trial phase I. First with the skin cancer. After that we will go to brain tumor and hopefully head and neck tumor in the near future.

\section{TRO: Did you start to do research on BNCT when you studied in Germany?}

Prof. Matsumura: At that time, I was not aware of BNCT. I have been in Göttingen, Germany for two times. The first time in Göttingen, I was in my fifth year residency, which means clinical training as a neurosurgeon in Germany. I had to perform various neurosurgical operations every day. Since the number of the operations was 10 times higher compared to Japanese University Hospitals, I gained lots of experiences for my surgical skills from 1984 to 1986. I also started to study neuropathological analysis of the brain tumor, using flow cytometry because there was a huge independent Neuropathological Department in Goettingen, where I had a very nice mentor, Prof. Hori. And I also obtained the "Doktor der Medizin" (similar to PhD) in Germany.

The second time, I was in the Biomedical NMR (BiomedNMR)—a research laboratory at the Max-Planck Institute for Biophysical Chemistry. I was involved in functional MRI, diffusion-weighted imaging (DWI) and also diffusion weighted MR spectroscopy (DWS) by using rat brain ischemia model. We started this project in 1992 with several pos-doc fellows from our department and we still have co-workers at this laboratory at the moment.

With the experience at the Max-Planck Institute, I could gain research experiences with researchers in various fields and this experience is of extreme value for our current project with interdisciplinary team members from medicine to physics and also other specialties, including mathematician, medical engineering, clinical scientist, etc., towards the realization of accelerator-based in-hospital BNCT. At first, we have different languages. Now we are a strong team in creating the accelerator for BNCT. 


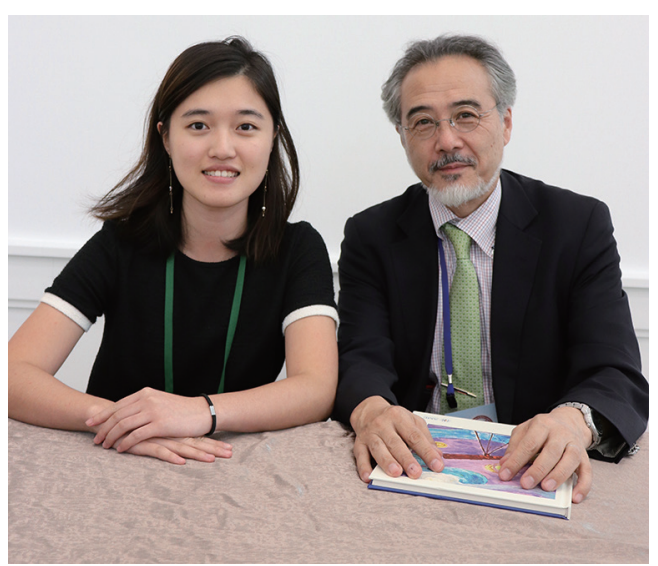

Figure 3 Photo with Prof. Akira Matsumura after the interview.

TRO: Do you bave any suggestions for young researchers who would like to devote into BNCT?

Prof. Matsumura: BNCT is an interdisciplinary project. When I studied in BNCT in the beginning, I couldn't understand what the physicists were saying. For example, when they were talking about neutron flux or neutron fluence. These are totally different language from medical. For physicists, it was also different language for them in medicine. For example, they didn't understand clinical study, phase I, phase II, and phase III. But if you are in the team, you can get same language as the group grows. So I suggest young researchers to get involved in the interdisciplinary works and learn from different specialties. Then you can have a very good result in comparison when you work only within your own small field. You can have a wider image and idea. That's very important for young researchers (Figure 3).

\section{Acknowledgments}

Funding: None.

\section{Footnote}

Provenance and Peer Review: This article was commissioned by the editorial office, Therapeutic Radiology and Oncology for the series "Meet the Professor". The article did not undergo external peer review.

Conflicts of Interest: The author has completed the ICMJE uniform disclosure form (available at http://dx.doi. org/10.21037/tro.2018.11.04). The series "Meet the Professor" was commissioned by the editorial office without any funding or sponsorship. Wei-En Fan reports that she is a full-time employee of AME publishing company (publisher of the journal). The author has no other conflicts of interest to declare.

Ethical Statement: The author is accountable for all aspects of the work in ensuring that questions related to the accuracy or integrity of any part of the work are appropriately investigated and resolved.

Open Access Statement: This is an Open Access article distributed in accordance with the Creative Commons Attribution-NonCommercial-NoDerivs 4.0 International License (CC BY-NC-ND 4.0), which permits the noncommercial replication and distribution of the article with the strict proviso that no changes or edits are made and the original work is properly cited (including links to both the formal publication through the relevant DOI and the license). See: https://creativecommons.org/licenses/by-nc-nd/4.0/.

\section{References}

1. Fan WF. Interview with Prof. Akira Matsumura: the accelerator-based clinical trial of BNCT for melanoma will be started in 2019. Asvide 2018;5:895. Available online: http://www.asvide.com/article/view/28680

(Science Editor: Wei-En Fan, TRO, tro@amegroups.com)

doi: 10.21037/tro.2018.11.04

Cite this article as: Fan WE. Interview with Prof. Akira Matsumura: the accelerator-based clinical trial of BNCT for melanoma will be started in 2019. Ther Radiol Oncol 2018;2:57. 